\title{
Clinical problems in hepatitis in childhood King's College Hospital experience 1970-73
}

\author{
Alex P. Mowat \\ M.B., Ch.B., M.R.C.P., D.C.H.
}

ROGER WILLIAMS

M.D., F.R.C.P.

The Department of Child Health and The Liver Unit, King's College Hospital Medical School

IN arranging the programme for this meeting we have been conscious of the problems encountered in the investigation and management of children referred to the Department of Child Health and Liver Unit, King's College Hospital, with acute and chronic hepatitis. Two areas of particular concern are the frequent failure to establish the cause of the hepatitis and the difficulty in assessing the value of therapy. We do not plan to summarize our experience but to highlight some of the major clinical problems in the hope that during the course of the meeting some progress can be made in clarifying them.

The first group to consider are those infants with the Neonatal Hepatitis Syndrome or its sequelae, of which we have seen approximately one hundred cases in the last 3 years. Some of the outstanding problems that these infants present are listed in Table 1. A

TABLE 1. Problems in neonatal hepatitis syndrome

Non-laparotomy diagnosis of biliary atresia

Surgical management of biliary atresia

Aetiological diagnosis

Assessment of prognosis in neonatal hepatitis

Therapy of neonatal hepatitis

major clinical difficulty is to distinguish those who require laparotomy to exclude surgically correctable biliary atresia or a choledochal cyst, knowing that laparotomy should be avoided in hepatitis (Thaler and Gellis, 1968) and that for the majority of patients with biliary atresia surgery is unhelpful (Alagille et al., 1969). Standard liver function tests are of little value but percutaneous liver biopsy (Brough and Bernstein, 1969), ${ }^{131}$ I-Rose Bengal excretion test (Maksoud et al., 1971), determination of serum lipoprotein-X concentrations (Poley et al., 1972), and serum bile salt patterns (Javitt et al., 1973), have each been claimed to distinguish infants with patent extrahepatic biliary tracts from those with biliary atresia. Considerable experience is required for the correct interpretation of liver biopsies. The ${ }^{131}$ I-Rose

Correspondence: Dr Alex P. Mowat, The Department of Child Health, King's College Hospital Medical School, Denmark Hill, London, S.E.5.
Bengal excretion test may give false negative results $\frac{2}{\circ}$ when there is urinary contamination of faeces, and 3 . false positive results when there is complete choles-if tasis. The last two techniques mentioned have not $i r$ been fully evaluated.

Surgical treatment of biliary atresia is far from

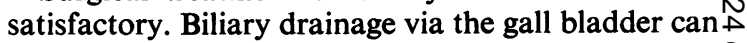
be established in less than $10 \%$ of cases (Alagille은 et al., 1969). For a minority of the remainder, biliary drainage may be affected by a hepatic portoenteros- $\subseteq$ tomy (Kasai et al., 1968), but it has yet to be shown that this influences prognosis (Kobayashi et al., $\overrightarrow{0}$ 1973).

Although we have systematically and prospe tively studied our cases (Porter et al., 1972) for knowaro genetic, infectious, or other exogenous causess (Mowat, 1972) in over $80 \%$ of cases none waso identified. If it is true that $25 \%$ die of liver diseaseo in infancy, $50 \%$ go on to chronic liver disease, while $25 \%$ make a complete recovery (Silverman, Roy and $\vec{\circ}$ Cozzetto, 1971), what are the factors which deter- 3 mine the outcome? Is it the cause or the response in? the infant, as would seem to be the case in, for ex-? ample, genetic deficiency of Alpha-1-antitrypsin? Will systematic investigation of, for example, im 3 . munological responses or serum bile salts be helpfulo in trying to identify those who recover spontaneously. and those who might require therapy?

When we consider therapy, there are even greater problems. Not one of the twelve suggested forms of treatment for Neonatal Hepatitis Syndrome listed 7 in Table 2 has been subjected to controlled trials. Are any to be seriously advised for our patients? Corticosteroids have their advocates (Kaye, 1969) but an equal number of paediatricians seem to be sufficiently convinced that they are without valuew in this situation so that we often have difficulty in getting patients admitted to a randomly allocatedo controlled trial (Mowat, Stroud and Williams, 1973) because the referring paediatrician is firmly of one or other viewpoint. Can we in fact define a group of sufficient homogeneity, particularly with regard to prognosis, to resolve this controversy by a properly $\underset{\mathbb{D}}{\mathrm{D}}$ conducted controlled trial? 
TABle 2. Suggested therapy for neonatal hepatitis

(1950-73: English Language Literature)

Milk-intramuscular injection

Dimercapto-propil-phthalmic acid

Corticosteroids

A.C.T.H.

Methoxyphenyl-dithio-cyclopentene

Dietary substances-unidentified

Amino acids

Vitamin B12

Mud poultices over liver

'Neoperhepar'

Immunosuppressives

Cholestyramine

Phenobarbitone

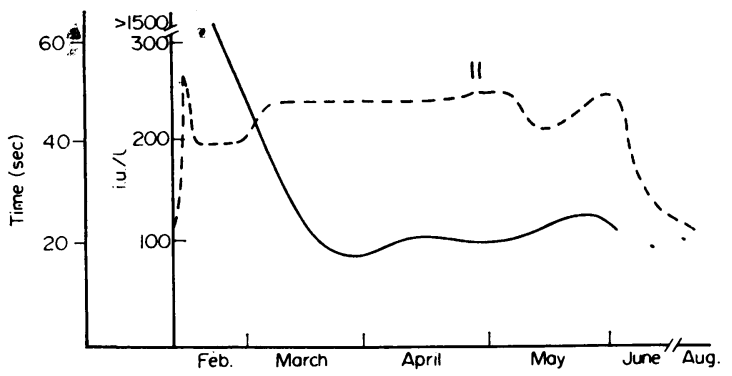

FIG. 1. Schematic illustration of the different time course of changes in serum aspartate transaminase levels (i.u./l.) and prothrombin times (sec) during the course of fulminant hepatitis with encephalopathy and spontaneous haemorrhage in a 6-year-old girl treated with corticosteroids and fresh frozen plasma. -, aspartate transaminase; - - , prothrombin time.

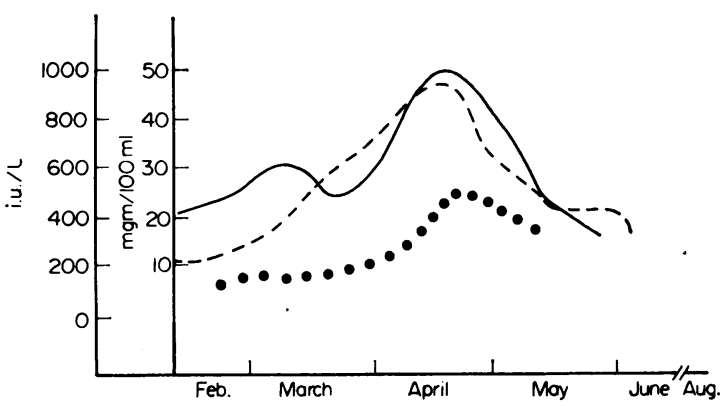

Fig. 2. Serum bilirubin ( $\mathrm{mgm} / 100 \mathrm{ml}$ ) and alkaline phosphatase (i.u./l) values from the same patient showing yet another pattern of change. - , serum bilirubin: total; , serum bilirubin: direct reading; $-\ldots$, serum alkaline phosphatase.

The second group of children that I wish to consider are much less numerous but cause major clinical difficulties. These are children with acute hepatitis complicated by encephalopathy and spontaneous haemorrhage. Figures 1 and 2 show schematically some of the disturbances of liver function in one of six such children admitted in the last 18 months. Encephalopathy had occurred on admission and on two subsequent occasions in the second and third hospital month. Orthodox treatment for fulminant hepatitis was given, together with corticosteroids in the form of prednisolone in a dose of $40 \mathrm{mg} / 24 \mathrm{hr}$ for the first 6 weeks and reduced over a 4 week period to $10 \mathrm{mg} / 24 \mathrm{hr}$. The serum aspartate transaminase level was very high early in the hospital course but fell rapidly. It appeared to rise slightly when the steroid dosage was reduced. To what extent these changes were produced by prednisolone is difficult to assess. One is aware that the use of corticosteroids in this situation is experimental. Most authorities (Cook and Sherlock, 1965; Williams, 1972; Saunders et al., 1972) consider that their efficacy is dubious but faced with a child in such a state and with even one report suggesting that they are of value in hepatitis (Katz et al., 1962), it is difficult to withhold them. A major problem was failure of hepatic synthesis of clotting factors without evidence of disseminated intravascular coagulation. Spontaneous bruising occurred until fresh frozen plasma transfusions were started early in the hospital course. These had to be continued regularly for $3 \frac{1}{2}$ months. Would there have been advantages in using plasma concentrates with higher concentrations of some clotting factors and less sodium? Would heparinization have helped (Rake et al., 1971)? In Fig. 2 the abnormalities of liver function tests indicate the severe cholestasis which persisted in spite of the fall in serum transaminase levels shown in Fig. 1. This single case study may indicate that corticosteroids have some beneficial effect on hepatocellular integrity as reflected in the serum transaminase levels, but they can hardly be claimed to have aided hepatic excretion, nor to have improved the synthesis of clotting factors. Cholestyramine was given after the first 10 weeks in hospital, but what part, if any, it played in the remission of cholestasis, is difficult to assess. The patient is now clinically well.

No cause was found for this child's hepatitis, nor was there a history of exposure to drugs, or contact with known cases of hepatitis. In other instances we have observed transient skin rashes which have suggested a viraemia but have never substantiated this. In one child the hepatitis might have been drug induced but this patient also showed a rise in serum antibody titre to cytomegalovirus. If hepatitis $A$ is the cause in the remainder, why does it follow such a fulminant course in these children? Is it variability in the hypothetical virus $A$ ? Is it dose related? If the reason is in the child, what parameters can be studied?

When we consider our experience with chronic hepatitis, with or without cirrhosis, we have the same problem. Aetiology undetermined in over $80 \%$ of cases, pathogenesis and prognosis uncertain, and no 
therapeutic agent of proven efficacy. Even when we do identify a possible cause, management is controversial. We recently have had under our care a 3-year-old boy who presented with a 5-month history of abdominal distension and hepatosplenomegaly and had the pathological features of chronic aggressive hepatitis associated with hepatitis B antigenaemia. Because of the pathological diagnosis we have treated this child with corticosteroids.His serum transaminases have coincidentally fallen from levels of approximately ten times normal to levels which are now one and a half times normal. After 9 months of therapy he still, however, has hepatitis B antigen in the peripheral blood. Have we caused the antigen to persist by using corticosteroids? Would immunoglobulin with a high titre of antibody to hepatitis B antigen have had any therapeutic role in this situation?

We hope that this meeting will serve a number of functions. With the help of the many experts we have enticed here, both speakers and guests, it should allow us to evaluate the significance of advances in some aspects of hepatitis in which there has been much recent growth in knowledge. In my review of our clinical experience of these three forms of hepatitis in infancy and childhood I have indicated how frequently the cause is undetermined, pathogenesis uncertain, and factors influencing prognosis are largely unknown and emphasized our concern that until adequately controlled trials of therapy are performed, we may do our patients as much harm as good. We hope, therefore, that this meeting will also indicate how these pressing clinical problems may be more clearly defined, investigated and resolved. Most importantly, the meeting should provide a stimulus for both clinical and laboratory research in paediatric liver disease.

\section{References}

Alagille, D., Borde, J., Habib, E.C. \& Dommergues, J.P. (1969) Biliary surgery for prolonged cholestasis in infant. Surgical findings in 128 cases. Archives Françaises de Pédiatrie, 26, 37.

Brough, A.J. \& Bernstein, J. (1969) Liver biopsy in the diagnosis of infantile obstructive jaundice. Pediatrics, 43, 519.
CoOK, G.C. \& ShERLoCK, S. (1965) Jaundice and its relation to therapeutic agents. Lancet, $\mathbf{i}, 175$.

JavitT, N.B., Morrissey, K.P., Siegel, E., Goldberg, H., $\complement$ GARTNER, L.M., HOLlander, M. \& KoK, E. (1973) Cholestatic syndromes in infancy; Diagnostic value of $\stackrel{\sim}{\rightarrow}$ serum bile acid pattern and cholestyramine administration. $\tau$ Pediatric Research, 7, 119.

Kasai, M., Kimura, S., Asakura, Y., Suzuki, H., TAIRA, Y. \& OSASHI, E. (1968) Surgical treatment of biliary atresia. Journal of Paediatric Surgery, 3, 665.

KatZ, R., Velasco, M., Klinger, J. \& Alessandri, H. (1962) ע Corticosteroids in the treatment of acute hepatitis in coma. Gastroenterology, 42, 258.

KAYE, R. (1969) In: Textbook of Paediatrics (Ed. by W.' E. Nelson, V. C. Vaughan and R. J. McKay), ninth edition, $\vec{c}$ p. 834. W. B. Saunders, Philadelphia, London and Toronto.

Kobayashi, A., Utsunomiya, T., OHbe, Y. \& Shimusu, K. Z (1973) Ascending cholangitis after successful surgical repair of biliary atresia. Archives of Diseases in Childhood, $48,697$.

Maksoud, J.G., Thom, A.F., Kiefer, J. \& Pinto, V.A. (1971) Fecal excretion of ${ }^{131} \mathrm{I}-$ Rose Bengal in diagnosis of obstruc- + tive jaundice in infancy with special reference to biliary atresia. Pediat rics, 48, 966.

Mowat, A.P. (1972) Liver disease in infancy and childhood. Medicine, 8, 582.

Mowat, A.P., Stroud, C.E. \& Williams, R. (1973) Corticosteroids in neonatal hepatitis. British Medical Journal, 2, 50.

Poley, J.R., Smith, A.I., Boon, D.J., Bhatia, M., Smith, C.W. \& Thompson, J.B. (1972) Lipoprotein $X$ and the $\mathscr{V}$ double ${ }^{131} I$-Rose Bengal test in the diagnosis of prolonged $\perp$ infantile jaundice. Journal of Paediatric Surgery, 7, 660.

PorTer, C.A., Mowat, A.P., Cook, P.J.L., HaYNes, D.W. Shilkin, K.B. \& Williams, R. (1972) Alpha-1-antitrypsin deficiency and Neonatal Hepatitis. British Medical Journal, 3, 435.

Rake, M.O., Flute, P.T., Shilkin, K.B., Lewis, M.L., 文 WiNCH, J. \& Williams, R. (1971) Early and intensive therapy of intravascular coagulation in acute liver failure. Lancet, ii, 1215.

Saunders, S.J., Hickman, R., MacDonald, R. \& TerBLANCHE, J. (1972) Treatment of acute liver failure. Progress in Liver Disease (Ed. by $\mathrm{H}$. Popper and F. Schaffner), Vol. 4, p. 333. Grune and Stratton, N.Y. and London.

Silverman, A., Roy, C.C. \& Cozzetto, F.J. (1971) Paediatric Gastroenterology, p. 292. C. V. Mosby Co., St. Louis.

Thaler, M.M. \& Gellis, S.S. (1968) Studies in neonatal hepatitis and biliary atresia, 1. Long-term prognosis of neonatal hepatitis. American Journal of Diseases in Childhood, 116, 257.

Williams, R. (1972) Problems of fulminant hepatic failure. British Medical Bulletin, 28, 4. 